\title{
ASPEK BIOTEKNIK DALAM PEMANFAATAN SUMBERDAYA IKAN TERI DI PERAIRAN PALABUHANRATU KABUPATEN SUKABUMI
}

\author{
(Bio-Technique Aspect of Anchovy Resources Utilization in Palabuhanratu Water- \\ Sukabumi District)
}

\author{
Diniah $^{1}$, Moch. Prihatna Sobari ${ }^{1}$ dan Indah Primadianti ${ }^{2}$
}

\begin{abstract}
The research objective to lay open aspects of technique and bio-technique in optimal anchovy resources utilization in Palabubanratu water in order to anchovy resources can be exploited on the responsible fisheries condition. Its calculation is done to use approach Clark, Yoshimoto and Pooley (CYP), Walter-Hiborn (W-H) and Fox Algorithm models. This research use time series data from 1997 until 2007. The result show that the construction of bagan rakit in Palabubanratu water consisted of the bagan house, bagan net, anjanganjang and roller. In its operational, they use 6 units of carrosene lamps. During period 1997 to 2007, amount of unit and effort of bagan rakit to tend to increase, while production of anchory tend to decrease and increasing to productivity of bagan rakit. Mean of actual production of anchovy resources 30.48 tons per year and actual effort is 26,816 trips per year. Estimation model of anchovy resources management in Palabuhanratu water appropriate Fox Algorithm model, with of static optimal production of equal to 38.51 tons per year and optimal effort of equal to 32,049 trips per year. Result of calculation at period 1997 to 2007 indicating that anchovy resources utilization in Palabubanratu water can be categorized not yet degraded and biological over fishing.
\end{abstract}

Keywords : bio-techniques aspect, anchovy, Palabuhanratu waters

\begin{abstract}
ABSTRAK
Penelitian ini bertujuan untuk mengungkapkan aspek teknik dan aspek bioteknik dalam pemanfaatan optimal sumberdaya ikan teri di Perairan Palabuhanratu agar sumberdaya ikan teri dapat dimanfaatkan secara berkelanjutan. Perhitungan dilakukan menggunakan pendekatan model Clark, Yoshimoto dan Pooley (CYP), Walter-Hiborn (W-H) dan Algoritma Fox. Penelitian ini menggunakan data time series dari tahun 1997-2007. Hasil penelitian menunjukkan konstruksi bagan rakit di Perairan Palabuhanratu terdiri atas rumah bagan, jaring bagan, anjang-anjang dan penggulung. Dalam operasionalnya alat tangkap ini dilengkapi dengan 6 buah lampu petromaks. Selama periode 1997-2007, jumlah unit dan effort bagan rakit cenderung meningkat, sedangkan produksi ikan teri cenderung menurun dan produktivitas bagan rakit cenderung meningkat. Produksi aktual rata-rata sumberdaya ikan teri sebesar 30,48 ton per tahun dengan tingkat upaya aktual mencapai 26.816 trip per tahun. Model estimasi pengelolaan sumberdaya ikan teri di Perairan Palabuhanratu yang lebih sesuai adalah model Algoritma Fox, dengan tingkat produksi optimal statik sebesar 38,51 ton per tahun dan tingkat upaya sebesar 32.049 trip per tahun. Hasil perhitungan pada periode 1997 2007 menunjukkan bahwa pemanfaatan sumberdaya ikan teri di Perairan Teluk Palabuhanratu dapat dikategorikan belum terdegradasi dan belum mengalami biological overfishing.
\end{abstract}

Kata kunci : aspek bioteknik, ikan teri, Perairan Palabuhanratu

\section{PENDAHULUAN}

Teri (Stolephorus sp.) merupakan salah satu komoditas penting dalam sektor perikanan tangkap di Palabuhanratu. Teri tersebut mayoritas ditangkap dari Perairan Palabuhanratu Kabupaten Sukabumi. Volume dan nilai produksi teri pada tahun 2007 mengalami penurunan dari tahun 2006, yaitu sebesar 90,52\% untuk volume dan 83,14\% untuk nilai. Produksi teri pada tahun 2007 mencapai 4.707 kg dengan nilai Rp37.582.000,(PPN Palabuhanratu 2007). Penurunan produksi teri di Perairan Palabuhanratu dapat merupakan indikasi terjadinya tangkap lebih (over-fishing). Penurunan produksi sumberdaya ikan merupakan akibat dari kegiatan eksploitasi sumberdaya ikan yang melebihi kapasitas lestarinya (suistainable yield). Sampai tahun 2007, alat penangkap ikan teri yang utama digunakan adalah bagan rakit. Melihat fenomena tersebut, maka perlu dilakukan upaya pengelolaan dalam pemanfaatan sumberdaya ikan teri di Perairan Teluk Palabuhanratu yang lebih

\footnotetext{
${ }^{1}$ Staf Pengajar Departemen Pemanfaatan Sumberdaya Perikanan, FPIK-IPB

${ }^{2}$ Alumni Program Studi Sosial Ekonomi Perikanan FPIK-IPB
} 
baik, sehingga sumberdaya ikan teri yang ada masih dapat menjadi dasar pertimbangan bagi perbaikan (recovery) stok ikan dalam kaitannya dengan pemanfaatan sumberdaya ikan secara berkelanjutan.

Perairan Palabuhanratu terletak di selatan Jawa Barat pada posisi $6^{0} 57^{\prime}$ $7^{\circ} 07^{\prime} \mathrm{LS}$ dan $106^{\circ} 22^{\prime}-106^{\circ} 33^{\prime} \mathrm{BT}$ yang merupakan satu sentra perikanan tangkap di Provinsi Jawa Barat. Perairan Palabuhanratu memiliki potensi besar dalam hal penyediaan ikan di masa yang akan datang. Seiring situasi ini, pemerintah setempat mencanangkan Palabuhanratu sebagai basis Kota Bahari. Rencananya penyediaan ikan di masa mendatang tentunya perlu diikuti dengan rencana pengelolaan dalam pemanfaatan sumberdaya ikan yang tersedia, diantaranya sumberdaya ikan teri.

Pendugaan stok sumberdaya ikan teri dapat dilakukan menggunakan pendekatan model bioteknis. Dalam penelitian ini digunakan tiga macam model, selanjutnya dilakukan analisis untuk mendapatkan model pengelolaan yang paling sesuai dengan kondisi Perairan Palabuhanratu. Tulisan ini mengungkapkan hal-hal menyangkut konstruksi dan produktivitas alat tangkap bagan rakit yang beroperasi di Perairan Palabuhanratu, serta menentukan jumlah produksi dan upaya tangkap optimum yang dapat dilakukan dalam pemanfaatan sumberdaya ikan teri di perairan tersebut.

\section{METODOLOGI}

Pengumpulan data di lapangan dilaksanakan pada Bulan April sampai dengan Bulan Juni 2008 bertempat di Kecamatan Palabuhanratu, Kabupaten Sukabumi. Penelitian menggunakan metode kuantitatif dengan pendekatan studi kasus. Satuan kasusnya adalah pemanfaatan sumberdaya ikan teri menggunakan bagan rakit di Perairan Palabuhanratu. Data primer diperoleh melalui wawancara terhadap 30 orang responden nelayan yang diambil secara purposive. Wawancara dilakukan searah berdasarkan kuesioner yang telah disiapkan. Data sekunder diperoleh dari instansi dan lembaga terkait, seperti Dinas Kecamatan Palabuhanratu, Pelabuhan Perikanan Nusantara Palabuhanratu, Badan Pusat Statistik serta literatur lainnya.

Analisis data yang dilakukan mencakup analisis teknik dan bio-teknik. Analisis teknik meliputi kajian terhadap keragaan unit penangkapan bagan rakit. Analisis bioteknik menggunakan pendekatan model CYP, W-H dan Algoritma Fox. Berdasarkan hasil perhitungan dari ketiga model tersebut, selanjutnya ditentukan model yang paling serasi dengan kondisi Perairan Palabuhanratu.

Analisis teknis meliputi kajian terhadap keragaan unit penangkapan bagan rakit, yaitu mengenai konstruksi bagan rakit, produktivitas alat tangkap, metode pengoperasian unit penangkapan, lokasi pengoperasian unit bagan serta komposisi hasil tangkapan bagan. Analisis bioteknis dilakukan untuk menggambarkan tingkat produktivitas dari upaya penangkapan (effort) dan menduga potensi sumberdaya ikan teri.

CPUE atau hasil tangkapan per upaya penangkapan digunakan sebagai indeks kelimpahan sumberdaya perikanan. Nilai ini diperoleh dari menggunakan rumus Gulland JA (1983):

$$
\text { CPUE }_{\mathrm{i}}=\frac{\text { Catch }_{i}}{\text { effort }_{i}} \quad i=1,2,3 \ldots \ldots \ldots n
$$

keterangan:

$C P U E_{i}=$ hasil tangkapan per upaya penangkapan teri pada tahun ke-i (ton per trip)

catch $_{i}=$ hasil tangkapan teri pada tahun ke-i (ton)

effort $_{i}=$ upaya penangkapan teri pada tahun ke-i (trip)

Analisis bio-teknis didekati menggunakan metode surplus produksi dari Schaefer MB (1954) diacu dalam (Sobari MP, Diniah, Widiastuti 2008; dan Clark et al. 1992). Hasil tangkapan maksimum lestari dilakukan dengan cara menganalisis hubungan antara upaya penangkapan $(E)$ dengan hasil tangkapan per upaya penangkapan (CPUE) meng-gunakan persamaan :

$h=q K E-\frac{q^{2} K}{r} E^{2}$

keterangan:

$h=$ hasil tangkapan teri (ton)

$E$ = tingkat upaya penangkapan teri (trip)

$r=$ laju pertumbuhan intrinstik ikan (ton)

$q=$ koefisien daya tangkap (ton)

$K$ = daya dukung lingkungan (ton)

Perolehan nilai $r, q$ dan $K$ dilakukan menggunakan teknik CYP (Clark, Yoshimoto dan Pooley), W-H (Walter-Hiborn) dan Algoritma Fox, dengan cara meregresikan persamaan : 


\section{a) Metode estimasi CYP}

$\ln _{\left(U_{t+1}\right)}=\frac{2 r}{(2+r)} \ln (q \cdot K)+\frac{(2-r)}{(2+r)} \ln \left(U_{t}\right)-\frac{q}{(2+r)}\left(E_{1}+E_{t+1}\right)$

Disederhanakan menggunakan Ordinary Lest Square (OLS):

$\ln _{\left(U_{t+1}\right)}=\alpha+\beta \ln \left(U_{t}\right)+\gamma\left(E_{t}+E_{t+1}\right)$

sehingga nilai $r, q$ dan $K$ dari persamaan [3] dapat diperoleh dengan rumus

$r=\frac{2(1-\beta)}{(1+\beta)}$

$q=\frac{\gamma}{(2+r)}$

$K=\frac{e^{\frac{a(2+r)}{(2 r)}}}{q}$

b) Metode estimasi W-H (Walter-Hiborn)

$\frac{U_{t+1}}{U_{t}}-1=r-\frac{r}{K q} U_{t}-q E_{t}$

atau

$y=\alpha-\beta U_{t}-\gamma E_{t}$

sehingga nilai $r, q$ dan $K$ dari persamaan [8] dapat diperoleh menggunakan rumus:

$$
r=\alpha ; \quad q=-\gamma ; \quad K=\frac{-r}{\beta q}
$$

\section{c) Metode estimasi Algoritma Fox}

$\frac{h}{E}=q K-\left(\frac{q^{2} K}{r}\right) E$

$C P U E=\alpha-\beta E$

Dengan nilai $x, y$ dan $z$ :

$z=\left(-\frac{\alpha}{\beta}\right)-E$

$x=\left(\frac{z}{U_{t}}\right)+\frac{1}{\beta}$

$y=\left(\frac{z}{U_{t}+1}\right) 1+\beta$

Dengan demikian nilai $r, q$ dan $K$ dari persamaan [9] dapat diperoleh menggunakan rumus:

$q=\left|\ln \frac{\left(\frac{x}{y}\right)}{z}\right| ; \quad K=\frac{\alpha}{\beta} ; \quad r=\frac{K q^{2}}{\beta}$
Keterangan :

$U=$ hasil tangkapan per upaya penangkapan

$E=$ tingkat upaya penangkapan

$a=$ nilai intersep

$\beta=$ slope atau kemiringan dari garis regresi

$a=$ nilai intersep

$b=$ slope atau kemiringan dari garis regresi

$r=$ laju pertumbuhan alami

$q=$ koefisien penangkapan

$K=$ daya dukung lingkungan (carrying capacity)

Berdasarkan rumusan di atas, maka kondisi pengelolaan sumberdaya ikan teri di Perairan Teluk Palabuhanratu secara optimal statik dapat dihitung dengan menggunakan rumus seperti yang disajikan pada Tabel 1.

\section{HASIL DAN PEMBAHASAN}

\subsection{Aspek Teknik}

Bagan rakit yang beroperasi di Perairan Palabuhanratu berukuran antara 6,5 $\mathrm{m} \times 6,5 \mathrm{~m}$ sampai dengan $11 \mathrm{~m} \times 11 \mathrm{~m}$. Secara umum konstruksi bagan rakit terdiri atas rumah bagan, rakit umumnya dari ikatan sejumlah bambu atau kombinasi blong, jaring bagan atau waring dan anjanganjang (Gambar 1). Bahan utama pembentuk bagan adalah bambu. Dalam pengoperasiannya, alat tangkap ini dilengkapi dengan lampu petromaks.

Jumlah bagan rakit di PPN Palabuhanratu berfluktuasi dan cendeung meningkat selama periode 1997-2007 (Gambar 2). Pada tahun 2007 bagan rakit berjumlah 267 unit, namun hanya sebagian unit bagan rakit yang beroperasi, umumnya bergantung pada musim penangkapan ikan. Berdasarkan data bulanan selama periode 1997-2007, bagan rakit lebih banyak dioperasikan pada bulan April-Mei dan Agustus sampai Oktober (Gambar 3). 
Tabel 1. Pola pengelolaan sumberdaya ikan teri pada model optimal statik

\begin{tabular}{|l|c|}
\hline \multicolumn{1}{|c|}{ Variabel } & Kondisi MSY \\
\hline Biomassa $(x)$ & $\frac{K}{2}$ \\
\hline Catch $(h)$ & $\frac{r \cdot K}{4}$ \\
\hline Effort $(E)$ & $\frac{r}{2 q}$ \\
\hline
\end{tabular}

Sumber : Clark et al. (1992), Fauzi A (2006)

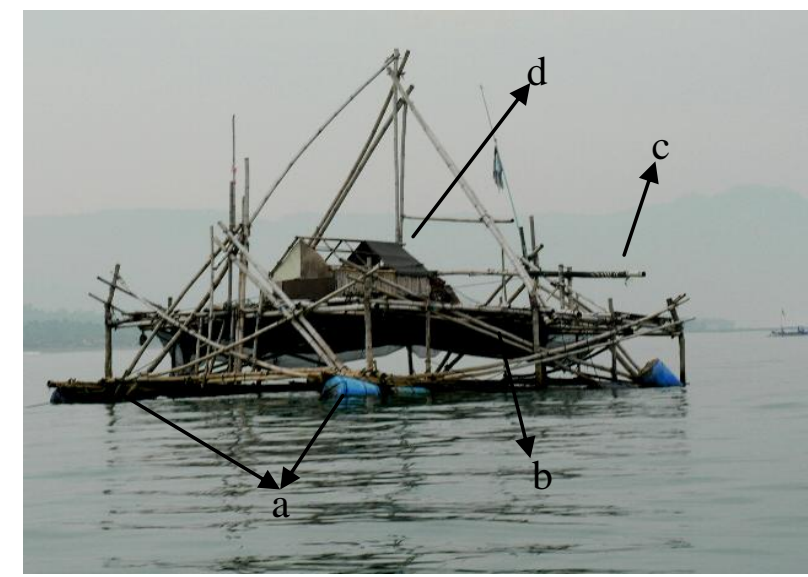

Keterangan :

$\mathrm{a}=$ rakit dari blong $; \mathrm{b}=$ waring $; \mathrm{c}=$ roller $; \mathrm{d}=$ rumah bagan

Gambar 1. Konstruksi bagan rakit di Perairan Palabuhanratu

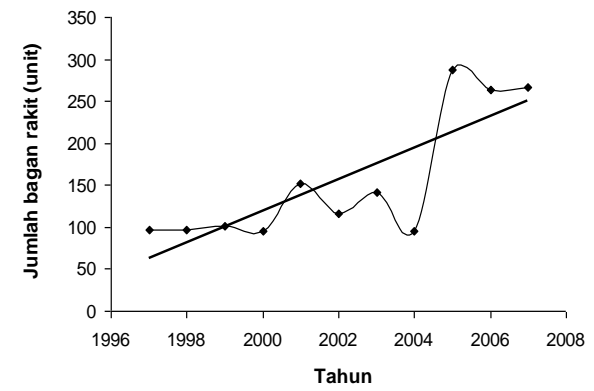

Gambar 2. Perkembangan jumlah bagan rakit periode 1997-2007

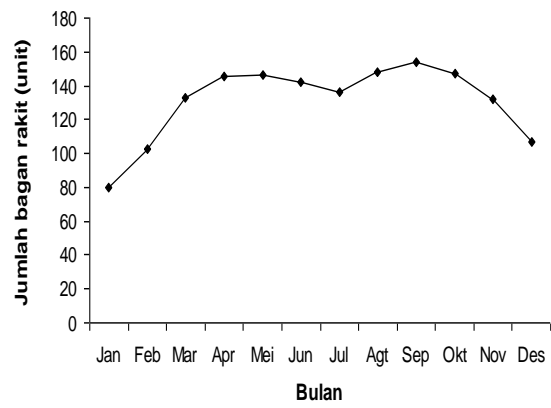

Gambar 3. Jumlah rata-rata bulanan bagan rakit yang dioperasikan
Bagan rakit dioperasikan one day fishing atau beroperasi hanya satu hari. Berangkat dari fishing base sekitar jam 16.00 dan kembali di fishing base sekitar jam 06.00 keesokan harinya. Operasi penangkapan ikan dibagi dalam tiga tahap, yaitu tahap persiapan, setting dan hauling. Dalam tahap persiapan dilakukan penya- laan enam buah lampu petromaks. Tahap setting adalah tahap penurunan jaring bagan ke dalam laut dan diikuti dengan pemasangan lampu hingga $1 / 2-1$ meter di atas permukaan laut. Setelah tampak banyak ikan di bawah lampu, lalu dilakukan hauling atau pengangkatan jaring. Jaring diangkat menggunakan alat 
bantu roller dengan perlahan-lahan hingga cepat agar ikan yang telah terkumpul tidak berpencar kembali. Proses hauling pada saat musim ikan bisa dilakukan 1/2-1 jam sekali, sehingga secara keseluruhan proses hauling per trip bisa mencapai 10 kali. Pada saat musim biasa, hauling dilakukan sekitar 5 kali bergantung pada kelimpahan ikan tangkapan yang diperoleh saat operasional. Daerah pengoperasian bagan umumnya di sekitar Perairan Teluk Palabuhanratu, antara lain di Perairan Karang Khau - kirakira 3 mil dari PPN Palabuhanratu, di PerairanTanjung Resmi atau ke arah timur di Perairan Cemara yang posisinya tidak jauh dari PPN Palabuhanratu. Intensitas pengoperasian bagan rakit cenderung meningkat selama 1997-2007 (Gambar 4) dengan jumlah trip tertinggi terjadi pada tahun 2005.

Hasil tangkapan utama bagan rakit bergantung pada musim ikan, antara lain adalah teri (Stolephorus spp.), cumi-cumi (Loligo sp.) dan petek (Leiognathus spp.). Jumlah hasil tangkapan utama per jenis ikan lebih sedikit dibandingkan hasil tangkapan sampingan, baik di musim puncak ataupun musim paceklik. Hasil tangkapan bagan rakit di PPN Palabuhanratu secara umum meningkat selama periode 1997-2007 dengan produksi tertinggi pada tahun 2005, namun hasil tangkapan teri cenderung menurun (Gambar 5). Persentase perolehan hasil tangkapan teri menurun selama 1997-2007 dibandingkan jenis hasil tangkapan bagan rakit lainnya (Gambar 6). Produksi teri yang menurun juga terjadi di belahan pantai Sumatera bagian barat lainnya, yaitu di kabupaten Agam (Sobari dan Muzakir 2009). Produktivitas bagan rakit secara umum meningkat selama periode 19972007, namun khusus tangkapan teri produk-tivitasnya menurun (Gambar 7).

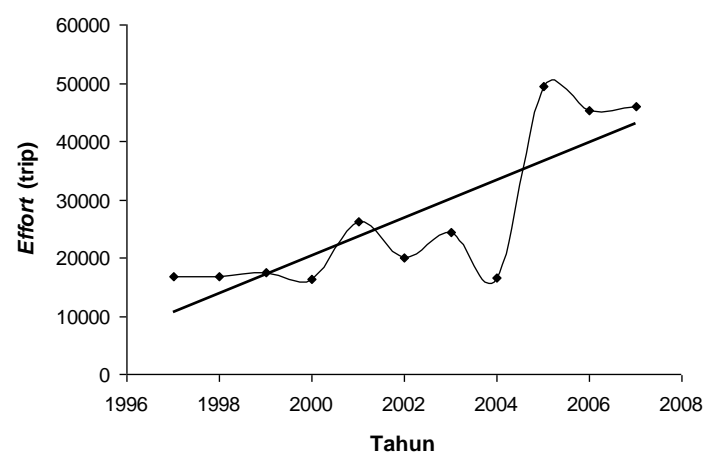

Gambar 4. Perkembangan jumlah effort (trip) bagan rakit periode 1997-2007

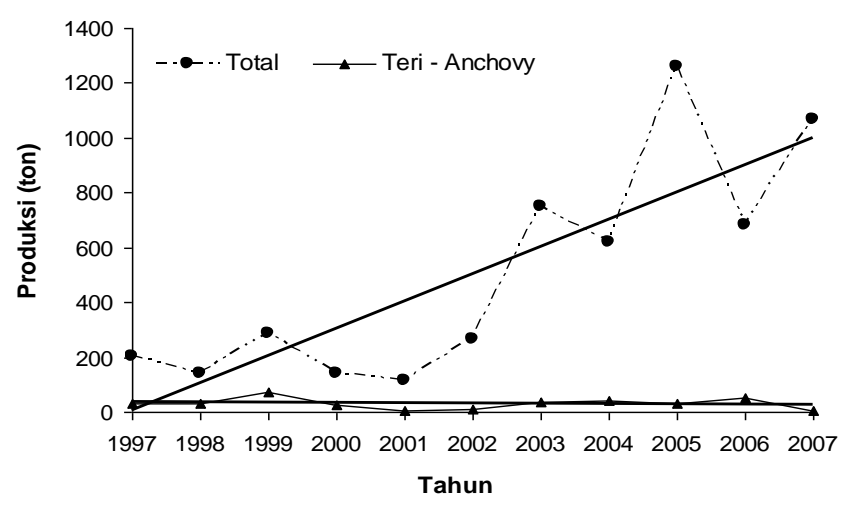

Gambar 5. Perkembangan hasil tangkapan bagan rakit dan teri periode 1997-2007 di PPN Palabuhanratu 


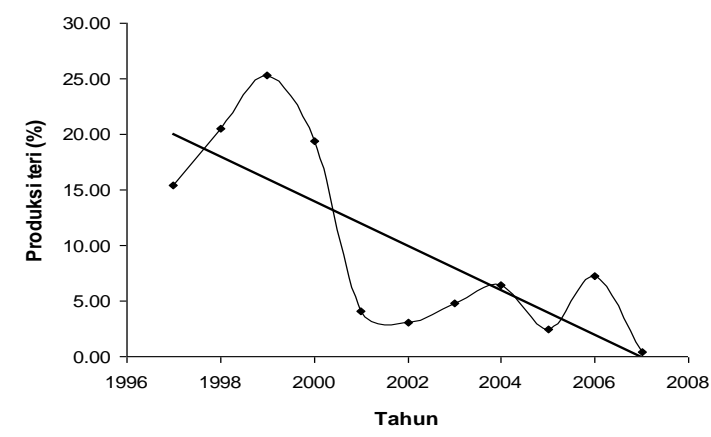

Gambar 6. Perkembangan persentase hasil tangkapan teri periode 1997-2007 di PPN Palabuhanratu

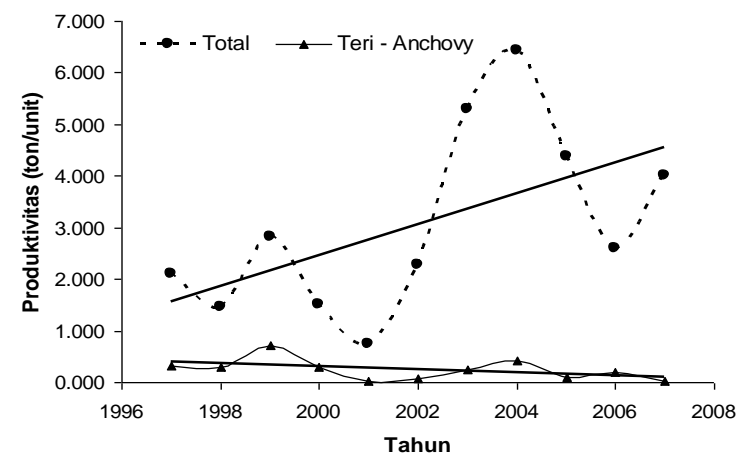

Gambar 7. Produktivitas bagan rakit periode 1997-2007 di PPN Palabuhanratu

\subsection{Aspek Bioteknik}

Nilai CPUE unit penangkapan bagan rakit untuk hasil tangkapan teri berfluktuasi dan cenderung menurun selama periode 1997-2007. Nilai CPUE bagan rakit berkisar antara 0,0001 sampai 0,0042. Nilai CPUE paling rendah yaitu pada tahun 2007 dan yang terbesar pada tahun 1999. Berarti bagan rakit yang paling produktif dari tahun 1997-2007 terjadi pada tahun 1999.

Hubungan antara CPUE dan Effort sumberdaya ikan teri digambarkan dalam persamaan $\mathrm{y}=-5^{\mathrm{E} 08 \mathrm{x}}+0,0028$ (Gambar 8 ). Trendline pada hubungan tersebut memperlihatkan kecenderungan menurun. Demikian juga yang terjadi di wilayah perairan Kabupaten Agam (Sobari dan Muzakir 2009). Kondisi ini tentunya perlu menjadi perhatian bagi pemanfaat sumberdaya teri.

Berdasarkan hubungan tersebut, dengan model estimasi CYP diperoleh koefisien pertumbuhan $(r)$ sumberdaya ikan teri akan tumbuh secara alami tanpa ada gangguan dari gejala alam mau pun kegiatan manusia sebesar 1,54 ton per tahun. Koefisien alat tangkap (q) mengindikasikan bahwa setiap peningkatan satuan upaya penangkapan akan ber- pengaruh sebesar 0,000006 ton per trip. Daya dukung lingkungan $(K)$ menunjukkan kemampuan ekosistem mendukung produksi sumberdaya ikan teri sebesar 52,91 ton per tahun. Begitu pula selanjutnya yang terjadi dengan menggunakan model $\mathrm{W}-\mathrm{H}$ dan Algoritma Fox (Tabel 2). Nilai koefisien pertumbuhan model Algoritma Fox merupakan angka terkecil $(0,87)$ diantara ketiga model yang digunakan, namun menunjukkan koefisien tangkapan $(0,0001$ ton per trip) dan daya dukung $(177,01$ ton per tahun) terbesar.

\section{1) Produksi Lestari}

Hasil estimasi produksi lestari ditunjukkan dalam Tabel 3. Rata-rata produksi lestari sumberdaya ikan teri di Perairan Teluk Palabuhanratu selama periode 19972007 berturut-turut sebesar 75,71 ton untuk model CYP, 42,67 ton untuk model W-H dan 31,41 ton untuk Algoritma Fox. Hal ini menunjukkan bahwa sumberdaya ikan teri di Perairan Teluk Palabuhanratu dalam rentang waktu dari tahun 1997-2007 belum mengalami overfishing secara biologi atau biological overfishing, karena rata-rata produksi aktual masih berada dibawah nilai rata-rata produksi lestari. 
Dalam model estimasi CYP (Gambar 9a) dan W-H (Gambar 9-b) sebagian besar volume produksi aktual sumberdaya ikan teri periode 1997-2007 berada di dalam kurva produksi lestari. Kondisi ini mengindikasikan bahwa kemampuan sumberdaya ikan untuk memperbarui diri belum berkurang. Dengan model estimasi Algoritma Fox (Gambar 9-c), hampir separuh volume produksi aktual sumberdaya ikan teri berada di luar kurva produksi lestari. Berdasarkan ketiga gambar tersebut dapat dinyatakan bahwa nilai optimal pemanfaatan sumberdaya ikan teri belum terlampaui pada kegiatan penangkapan yang aktual.

Berdasarkan Gambar 9 dapat diperoleh nilai optimal dari pemanfaatan sum- berdaya ikan teri di Perairan Palabuhanratu seperti tercantum di dalam Tabel 4 . Jika dibandingkan dengan Tabel 3 dan Gambar 8 yang menunjukkan kondisi lapangan, maka model yang paling sesuai untuk menduga model pengelolaan sumberdaya ikan teri di Perairan Palabuhanratu adalah model Algoritma Fox. Hal ini ditunjukkan oleh persentase produksi dan effort aktual terhadap nilai MSY yang tertinggi pada model Algoritma Fox dibandingkan dengan kedua model lainnya dengan nilai $79,15 \%$ untuk produksi dan 83,67 \% untuk effort. Pada model CYP dan $\mathrm{W}-\mathrm{H}$ pendugaan nilai optimal lestarinya (MSY) terlalu tinggi (over estimate).

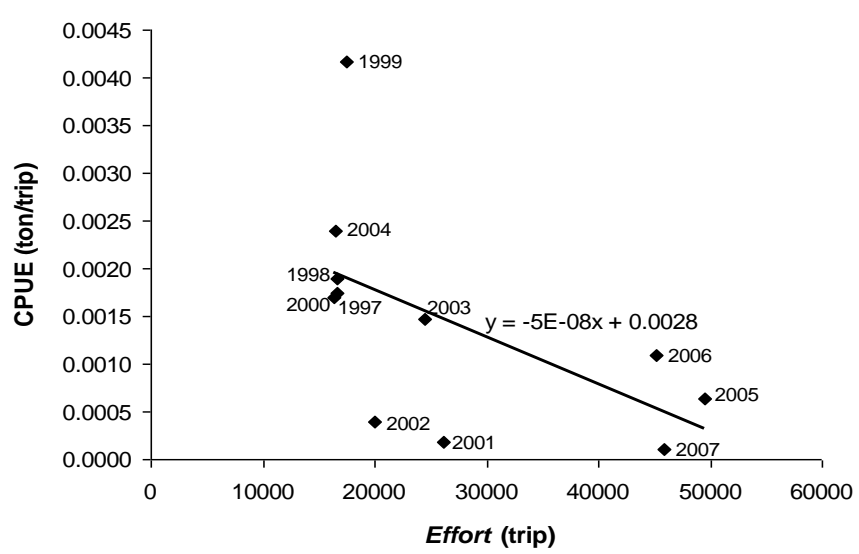

Gambar 8. Hubungan CPUE dan Effort Tahun 1997-2007

Tabel 2. Hasil Estimasi Parameter Bioteknik

\begin{tabular}{|c|r|r|r|}
\hline Model Estimasi & \multicolumn{3}{|c|}{ Parameter Biologi } \\
\hline & $\boldsymbol{r}$ (ton per tahun) & $\boldsymbol{q}$ (ton per trip) & $\boldsymbol{K}$ (ton per tahun) \\
\hline CYP & 1,54 & 0,000006 & 52,91 \\
\hline W-H & 2,53 & 0,00003 & 84,17 \\
\hline Algolitma Fox & 0,87 & 0,0001 & 177,01 \\
\hline
\end{tabular}

Tabel 3. Produksi aktual dan hasil estimasi produk lestari

\begin{tabular}{|c|r|r|r|r|}
\hline \multirow{2}{*}{ Tahun } & \multirow{2}{*}{$\begin{array}{c}\text { Produksi } \\
\text { Aktual }\end{array}$} & \multicolumn{3}{|c|}{ Produksi Lestari } \\
\cline { 3 - 5 } & 31,56 & 50,59 & W-H & Algoritma Fox \\
\hline 1997 & 29,11 & 50,59 & 36,39 & 29,66 \\
\hline 1998 & 72,99 & 53,01 & 36,39 & 29,66 \\
\hline 1999 & 27,65 & 49,62 & 37,71 & 30,62 \\
\hline 2000 & 4,64 & 76,08 & 35,84 & 29,26 \\
\hline 2001 & 8,01 & 59,66 & 48,00 & 37,21 \\
\hline 2002 & 36,04 & 71,62 & 41,13 & 33,03 \\
\hline 2003 & 39,50 & 50,11 & 46,37 & 36,33 \\
\hline 2004 & 31,46 & 129,14 & 36,11 & 29,46 \\
\hline 2005 & 49,64 & 120,45 & 48,69 & 27,05 \\
\hline 2006 & 4,71 & 121,88 & 51,55 & 31,99 \\
\hline 2007 & 30,48 & 75,71 & 51,19 & 31,29 \\
\hline Rata-rata & & 42,67 & 31,41 \\
\hline
\end{tabular}

Sumber: Diolah dari data primer 
Tabel 4. Perbandingan pemanfaatan aktual dan optimal statik

\begin{tabular}{|l|r|r|r|}
\hline \multicolumn{1}{|c|}{ Pemanfaatan } & \multicolumn{1}{c|}{ Aktual } & \multicolumn{1}{c|}{ MSY } & \% aktual terhadap MSY \\
\hline Pendekatan CYP & & & \\
\hline Produksi (h)(ton) & 30.48 & 203,71 & 14,96 \\
\hline Effort $(E)$ (trip) & 26.816 & 125.415 & 21,38 \\
\hline Pendekatan W-H & & & 57,14 \\
\hline Produksi (h)(ton) & 30.48 & 53.34 & 70,12 \\
\hline Effort (E)(trip) & 26.816 & 38.244 & 79,15 \\
\hline Pendekatan Algoritma Fox & & & 83,67 \\
\hline Produksi (h)(ton) & 30.48 & 38.51 & \\
\hline Effort $(E)$ (trip) & 26.816 & 32.049 & \\
\hline Sumber: Diolah dari data primer & & & \\
\end{tabular}

\section{2) Laju Degradasi}

Produksi aktual secara umum lebih kecil dibandingkan produksi lestarinya (Tabel 3). Hal ini menunjukkan bahwa sumberdaya ikan teri di perairan Palabuhanratu belum terdegradasi, seperti tampak dalam Gambar 10. Gambar 10 menunjukkan bahwa untuk semua model estimasi laju degradasi sumberdaya ikan teri berada di bawah laju standar dengan nilai 0,11 untuk model CYP, 0,18 untuk model W-H dan 0,22 untuk model Algoritma Fox. Hal ini berarti kondisi biological over fishing belum terjadi di Perairan Palabuhanratu.

\section{KESIMPULAN DAN SARAN}

\subsection{Kesimpulan}

1) Konstruksi bagan rakit di Perairan Teluk Palabuhanratu terdiri atas rumah bagan, jaring bagan, anjang-anjang dan penggulung. Dalam operasionalnya alat tangkap ini dilengkapi dengan lampu petromaks. Selama periode 1997-2007, jumlah unit, effort dan produktivitas bagan rakit memperlihatkan trendline yang meningkat, sedangkan produksi ikan teri sebaliknya. Produksi aktual rata-rata sumberdaya ikan teri di Perairan Teluk Palabuhanratu sebesar 30,48 ton per tahun dengan tingkat upaya aktual mencapai 26.816 trip per tahun.
2) Berdasarkan hasil perhitungan menggunakan pendekatan tiga model pengelolaan, maka model estimasi pengelolaan sumberdaya ikan teri di Perairan Palabuhanratu yang sesuai dari ketiganya adalah model Algoritma Fox, dengan tingkat produksi optimal statik sebesar 38,51 ton per tahun dan tingkat upaya sebesar 32.049 trip per tahun. Hasil perhitungan pada periode 1997-2007 menunjukkan bahwa pemanfaatan sumberdaya ikan teri di Perairan Teluk Palabuhanratu dapat dikategorikan belum terdegradasi dan belum mengalami bio-logycal overfishing.

\subsection{Saran}

Hasil perhitungan yang telah dilakukan menunjukkan bahwa peman-faatan sumberdaya ikan teri di Perairan Palabuhanratu belum mengalami kondisi biologycal overfishing, namun dengan menurunnya produksi ikan teri, maka disarankan tetap dilakukan kontrol terhadap jumlah unit dan effort bagan rakit. Selanjutnya disarankan untuk melakukan kajian lebih lanjut tentang laju depresiasi sumberdaya ikan teri melalui pendekatan bionomi. 


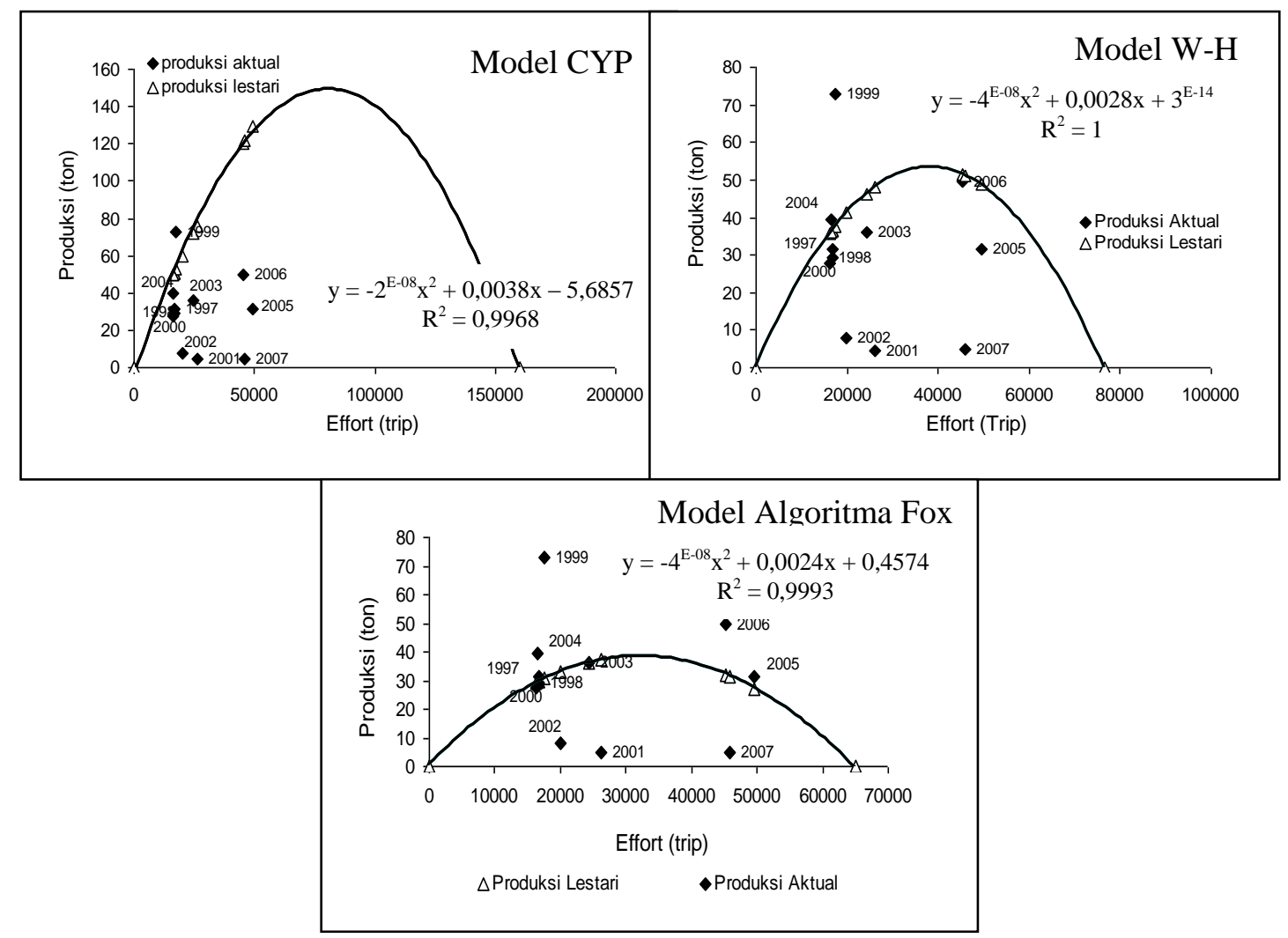

Gambar 9. Hubungan produksi lestari dan aktual periode 1997-2007

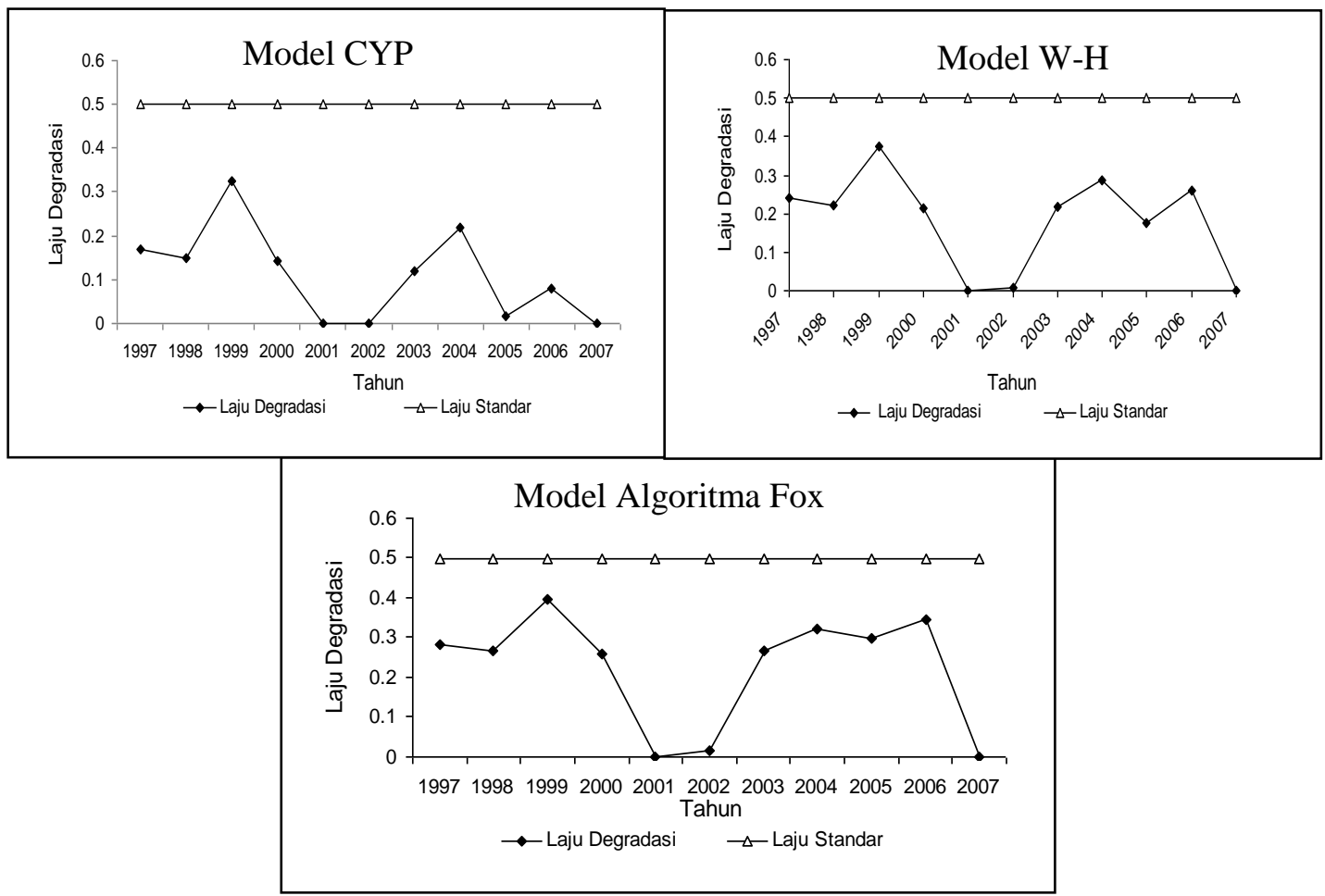

Gambar 10. Laju degradasi sumberdaya teri di Perairan Palabuhanratu 


\section{DAFTAR PUSTAKA}

Clark CW, SS Yoshimoto and SG Pooley. 1992. A bioeconomic analysis of the North Western Hawaiian Island lobster fishery. Marine Resource Economics $7(2)$ : $115-140$.

Fauzi A. 2006. Ekonomi Sumberdaya Alam dan Lingkungan: Teori dan Aplikasi. Jakarta: Penerbit PT Gramedia Pustaka Utama. 259 hal.

Gulland JA. 1983. Fish Stock Assessment: A Manual of Basic Methods. Chester New York - Brisbane- Toronto Singapore: John Willey and Sons. $233 \mathrm{pp}$.

[PPNP] Pelabuhan Perikanan Nusantara Palabuhanratu. 1997-2007. Statistik Perikanan tahun 1997-2007. Sukabumi : PPN Palabuhanratu.

Schaefer M. 1954. Some Aspects of the Dynamics of Populations Important to the Management of Commercial Marine
Fisheries. Bull. Inter-Am. Trop.Tuna. Comm. 1:27-56.

Sobari MP, Diniah, Widiastuti. 2007. Kajian Model Bionomi terhadap Pengelolaan Sumberdaya Ikan Layur di Perairan Palabuhanratu. [makalah seminar] Seminar Nasional Perikanan Tangkap. Desember 2007. Bogor: Departemen Pemanfaatan Sumberdaya Perikanan.

Sobari MP dan Muzakir. 2008. Kajian ekonomi pemanfaatan sumberdaya ikan teri di Kabupaten Agam, Provinsi Sumatera Barat. Buletin PSP (Jurnal Ilmiah Teknologi dan Manajemen Perikanan Tangkap) Volume XVII Nomor 3 Bulan Desember 2008, ISSN : 0251-286X. Bogor : Forum Komunikasi Kemitraan Perikanan Tangkan dan Departemen Pemanfaatan Sumberdaya Perikanan, Fakultas Perikanan dan Ilmu Kelautan, Institut Pertanian Bogor. Hal 373-381. 